\title{
Experiments with visible and invisible materials: designing and building an ambiance
}

\author{
Céline Drozd ${ }^{1, *}$, Virginie Meunier ${ }^{1}$, and Antoine Mabire $^{2}$ \\ ${ }^{1}$ Graduate School of Architecture of Nantes, AAU Laboratory, 44262 Nantes Cedex 2, France \\ ${ }^{2}$ Mabire\&Reich Agency, Graduate School of Architecture of Nantes, 44262 Nantes Cedex 2, France
}

\begin{abstract}
This article relies on a workshop called "materials of ambiances" that is taking place at the Graduate School of Architecture of Nantes. It aims for the students to question the qualities of ambiances within spaces with an approach through the concept of material, making them aware of invisible materials (ambiances) from the manipulation of visible materials (building materials). The experimentation with materials holds a significant place: the students are asked to build an ambiance device to create a sensory experience in order to highlight every sensory quality of a material capable of producing an ambiance. The materials used for this experiment are mostly from fields beyond architecture as to think of potential misappropriations. It is about making sure that the student tests by himself the materials and recreates the connection between data from the experiment, and the physical characteristics given by the manufacturers and industrialists. The pedagogical experience that we present aims at creating within students an interest for the built material, to develop ambiance intentions to qualify projected spaces, which are not always measurable but always noticeable. This article proposes to turn back to the way the qualities of ambiances are felt, the misappropriations of materials are perceived, as well as the perspectives on the evolution of the architectural design process. This contribution is illustrated by an ambiance device whose the name is "Cosmic dream" built in 2018/2019 by Marilou Bach, Hugo Falaise, Carole Lyssandre and Charlotte Say.
\end{abstract}

While using digital tools within architectural design can give the impression of distance with
concerns about body experience in architecture [1], environmental questions seem to have
resulted in a growing interest for the relation between humans and their environment, which
translates in particular into an aesthetical approach of ambiances [2]. Therefore, in order to
connect the technical and sensory dimensions of architectural design, a lecture given at the
Graduate School of Architecture of Nantes aims for students to question the qualities of
ambiances within spaces with an approach through the concept of material. This workshop,
called "materials of ambiances", grants a large part to the experimentation with materials to
make them work with invisible materials (ambiances) from the manipulation of visible ones
(building materials). Indeed, as Jean-Claude Prinz [3] suggests, materials "take part in the
general ambiance of a place. [...] By creating an exchange with our senses, they send us back

* Corresponding author: celine.drozd@crenau.archi.fr 
to sensations, emotions, values that elicit reactions of appropriation, acceptance or rejection" (p.8). Moreover, as Jacques Ferrier ${ }^{*}$ explains, in the current context of reduction of buildings' energy consumption, we should not forget that architecture, beyond the precise control of ambiances, is also a "question of atmosphere. Nowadays, it is possible to create environments that are more comfortable and more economical in terms of energy without sacrificing the architect's primary intention, which guides him to decide on an atmosphere." Following this objective, the pedagogical experience that we present aims at creating within students an interest in the built material, to develop ambiance intentions to qualify projected spaces, which are not always measurable but noticeable nonetheless.

\section{Experimenting with materials as a pedagogical way to design and build an ambiance}

As Grégoire Chelkoff [4] states, “(...) talking about architecture in terms of ambiance means conceiving it as a sensory culture of the inhabited environment. It requires a modal, rather than causal, approach regarding physical and sensory dimensions (...).” (p.19). In that sense, we offer at ENSAN an incremental approach on the pedagogy of architectural and urban ambiances throughout the training in architecture, from awareness in first year (Licence 1) to the design and building of an ambiance at Master's level, which allows to experience and live the proposed atmosphere. Over the course of the training years, the common objective of these different approaches is for the students to realise the importance of crossing the physical and sensory dimensions in the design and construction of an ambiance, so that they can, as Louis Kahn [5] explains, “(...) start from what is non-measurable, go through measurable means during the project and, ultimately, be non-measurable." (p.50-51). Therefore, in the Master's degree, the deliberate point is to make the students work on ambiance with their sensory component as an entry point into the design process. In fact, we agree with Grégoire Chelkoff [4] when he says that it would be beneficial to "refine the knowledge and the processes of training (of practices and ordinary experiences of spaces) (...) facing design modes that favour formalism, which tends to impose its vision or effects, or functionalism, which is often too reductive in terms of human variations of inhabiting." (p.19).

We made the choice of addressing the design of ambiance from the work on materials in order to connect material preoccupations (implementation of materials) with immaterial ones (ambiances). The joint work on visible and invisible materials is different from usual lectures on that subject in architecture school, which usually distinguish the lessons on the structural and physical characteristics on the one hand, and the poetic and symbolic elements on the other hand. To this end, we establish a pedagogy on the experimentation of materials that allows the students to place themselves within a "deliberately active and transformative dimension within the research process" [6] (p.2). By going beyond the stage of spatial outline, they are confronted to the reality of materials, to the consideration of ambiances and the complexity of uses.

Experimenting ambiances via materials is an approach that is still little developed, as Grégoire Chelkoff [6] stresses: "If we know about experimentations that are essentially constructive, we know less about those that are directly based on qualities or criteria regarding ambiance.” (p.5). Indeed, the concept of teaching by experimenting traditionally takes a constructive approach that aims at reproducing elements from reference buildings to

\footnotetext{
* Jacques Ferrier, on the sensory city, online: http://www.sensual-city.com/ consulted on 28/09/2018
} 
understand spatial forms and structural compositions. Without questioning their pedagogical interest, this is a partial approach to material, which we tried to overcome. We think that, as Tadao Ando [7] explains, "architecture is made of two elements. One is intellectual, since one needs to create a logical and clear space, with a logical or intellectual order. Furthermore, we need to use our senses to give life to space. Those are the two fundamental aspects of the creation of architectural space. One is theoretical and practical, the other is sensory and intuitive." (p.53). With the manipulation of materials, the sensory experience becomes a way to apprehend space and design it, for students who are future architects.

\section{2 "Materials of ambiances": objectives of and expectations from the workshop}

The students are expected to design and build an inhabited ambiance device, allowing to live a sensory experience that includes the body, or part of it. The design of that device relies essentially on one material, selected for its potential of ambiances. The point is for the students themselves to test the materials, and to re-establish the connection between the data from the experimentation, i.e. their own observations and analyses, and the physical characteristics provided by the manufacturers and suppliers, while going beyond this and reveal the material in all its qualities and potentialities. According to us, it seems indeed necessary to bridge theoretical knowledge and a physical, manual approach of material, as Peter Zumthor [8] does in his work: "the idea (is) that the task of creating architectural atmosphere also comes down to craft and graft." (p. 21). Therefore, some materials are analysed and studied to reveal an aesthetics of ambiances through an experience to be lived, which implies a particular position given the selected material. Moreover, the ambiance device includes climatic and ambiance conditions that are already within the studied site (solar radiation, natural light, air flow, rain, noise...). Those parameters are created and/or emphasised by artificial devices (radiator, speakers, fan, hairdryer, spotlight, smoke machine...), and it allows to reveal the ambiance qualities of the materials selected by the students, and to highlight senses besides vision.

The design of the device is composed of back and forth motions between different stages to reach its construction, then its perception within the built space: knowledge of the material via tests and manipulations to evaluate the possible transformations and transfigurations, narrative that leads to the formulation of an intention in terms of ambiance that stimulates creativity, definition of a scenario of sensitive experiences implying several senses and one or several body positions, outline of the device via the formalization of models on different scales to better envision the 1:1 scale construction, carry out survey of the ambiances in the implementation space for the device, in order to determine the adequate place for the projected ambiance intentions. The design process continues in the construction phase of the device, since adaptations for the system are not unusual at this stage. Lastly, the presentation of the ambiance device is accompanied by displays of the material, to introduce it to the school users in general. The device is also tested by asking a public who is not integrated to the class to experience the ambiance, so as to determine some feedback on the sensory experience of the device.

The materials used by the students are provided by suppliers who have been contacted, and who are interested in the experimental approach of this class. For the most part, they are coming from other fields than architecture, in order to consider possible other uses, and they were selected a-priori, depending on the ambiance potential they seemed to hold. Beyond the visual aspect, some of them have obvious sound and/or thermal insulation qualities, have materials with strong olfactory power, produce unprecedented sounds under certain 
conditions, reveal their characteristics upon touching, as opposed to what they offer to see, etc. This evocative potential, regarding sensations and emotions, is not always perceptible at first glance. This is why manipulation tests and the development of imagination are necessary stages to quickly overcome the emerging prejudices and open the scope of possibilities: "Architecture does not only implement spaces and compositions, but also materials that offer an array of perceptions. The implementation of materials that have been little transformed unfolds a range of evocations. Through their seeds, their surfaces, their textures, they provide perceptions that go beyond the strict architectural framework to include the perception of the material, its power, its rest." [9] (p.120).

To ensure that they will go beyond the first contact with the material, and to stimulate their creativity to fuel the design process, we ask the students to put together a narrative, a story around the material, which refers to the different senses, to a poetics, to an imagination... Indeed, as Nathalie Tornay [10] recalls, materials hold an imaginary dimension "that relies on metaphors and connotations to make sense" (p.93) and allow thus to develop within the design process "sensory aspects by games of surface, material, etc., making the sensory perceptions even more intense (vision, touch)." (p.92). Other authors [3, $11,12]$, such as Antoine Picon [13], also insist on the symbolic and cultural dimensions of the perception of materials: "(...) our body, similarly to the perceptions and sensations that represent its base, is marked by the society in which we are living. Indeed, we do not perceive our surroundings without the context in which we have grown up. This context, in a way, filters out the diversity in outside stimuli and gives them a shape. (...) This learning process happens in close relation to the materials, the tools, the instruments and the machines that are at our disposal." (p.61-62).

For example, we will explicit the work of a group of students that was produced with a piece of fabric, whose surface was made of glass beads and thus reflected the light (retroreflective fabric from the Super Black line by JRC Reflex)*. Usually, it is used for safety clothing, in particular in the road sector. Based on their manipulations, the students have developed an imaginary around a "cosmic" vocabulary to translate their sensations into a narrative: "Put down your foot... it sinks, then bounces back. Step by step, the material bends under your weight, then regains its original appearance. Surprisingly elastic, incredibly resistant $(\ldots)$ ! You feel like you are balancing, as if in the air, a moon landscape appears before your eyes (...). The light travels, dances with the fabric, reverberates. The ground blends with the walls, the walls with the ceiling. You lose the sensation of depth... You decide to change your viewpoint, and suddenly... A rainbow. A psychedelic spectrum crashes down onto your field of vision!"

The resulting device highlights the temporary deformation characteristics in the fabric, as well as its resistance, the silky touch, the thin rustle we can hear during the deformation, the lighting effects that are produced (fig.1).

The students introduce it: "The fabric that composes it, with its flexibility and fluidity, wraps around steel arms. Minimal, almost shy, it is still a long way from unveiling its hidden world. Without obvious invitation, the visitor has to come close and, like an explorer, to find an entry point. But this new universe is not reached easily. One needs skills, force and flexibility to expand the space and create a new dimension. That space is no longer a plan, but a moving volume in constant metamorphosis. Drawn in by this unique universe, disconnected from the outside world, the experiment has started. We are now starting an

* http://www.jrc-reflex.com/Products/SuperBlack.aspx 
immersive and sensory ride. The journey is strange, difficult but pleasant, led by a weakened gravity and a flexible, expandable medium. The material that makes the walls of this universe represents an incredible, almost improbable, paradox. Even though it is made of glass, it is soft to the touch in a soporific way, and has a mesmerizing flexibility. The body ultimately sits or lies down to enjoy the visual show. Similar to a psychedelic daydreaming, the glass material decomposes the light. Reflected and turned into a multi-coloured spectrum, it moves and accompanies its disturbed universe." The efforts made by the body to enter this space are proportional to the efforts the fabric makes to welcome its guest.
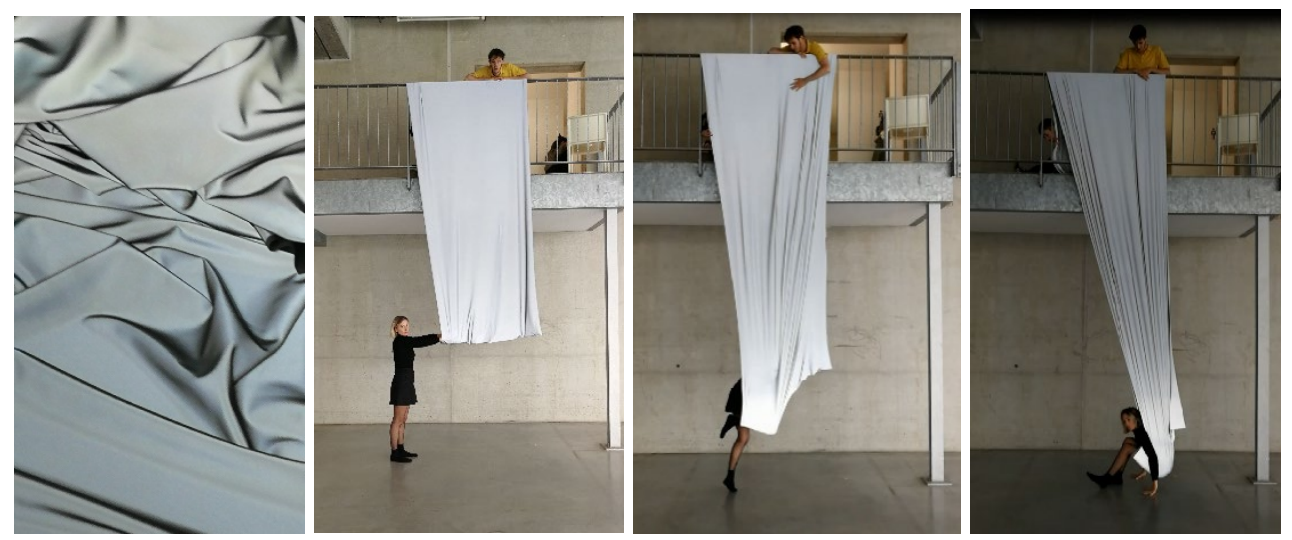

Fig. 1. Tests and manipulation by students with the retro-reflective fabric: silky aspect, deformation and resistance, lighting reflections.

The "cosmic" imagination that was developed by the students is recalled by the users of the device: "With this light, we feel like we're somewhere else... The little rainbow reflections are great!", "It's like a parallel world! It was almost stressful to be inside! Because you want to try every position, but it's not easy physically.", "To see the seam closing up again is almost like seeing the universe turning grey, it is very enveloping", "I feel like I'm in a very comfortable pouch... As if I was hovering above the ground, we're not touching anything, it's like flying!", "The material is elastic, it's like a hammock, you are falling towards the ground and the material... it's soft!" (fig. 2).
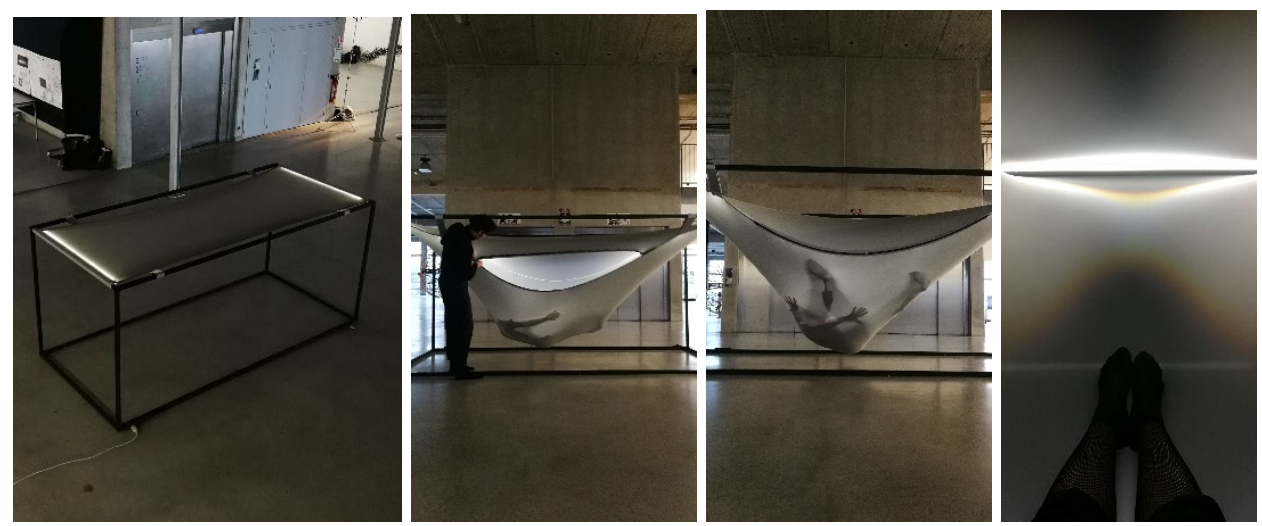

Fig. 2. Device from the outside to the inside.

\section{Pedagogical feedback on the evolution of architectural practice}


The subsequent session of the workshop allowed to identify some pedagogical contributions benefitting architectural design. Among those, we can mention the constitution of a reference corpus on singular materials that generate ambiances, but in particular a reference corpus on experienced ambiances, which will support architectural design and research. As Xavier Bonnaud [9] says, "in education, (...) a portion of the learning processes on design are accomplished in the domestication of the subjective reception of places, the ability to feel and perceive non-rational qualities a-priori, and to decipher the secret manufacturing conditions and to try mastering them." (p.34).

One of the purposes of this workshop is to encourage students to look differently at materials, to reveal their potentialities, and thus to go beyond the usual implementation of this material, to enrich the architectural design and construction. Some architects implement this approach, such as Antoine Mabire in the case of a house project in La Rochelle, in which a widespread constructive mode (concrete formwork blocks ÉCLAIR) was used in an unusual way: "The idea was to say: the walls are made like this, we insulate from the outside and our walls, they're like that. In the result, we will have an entry"*. Moreover, this is used for the aggregate of materials used throughout the different architectural production stages of the agency: “(...) We have constants. For example, we like using the material for what it's good at, and then we keep it visible, to establish ambiances"*. To this end, models are used during the design process, and they allow to project ambiances. The difficulty to translate the material into the different scales arises, as Antoine Mabire points out when mentioning the design of the vegetable processing area at the Lycée Rieffel in Saint Herblain, France (fig. $3 \& 4)$. Three of the walls are made out of weaved wicker: "We made (...) a big part of the model where we actually wove wicker, but we faced something unexpected: finding the right scale for the material. We tried different things, we wanted a rather big scale to see well. But the problem was that wicker can be worked on only when it is wet..."* (fig. 5).
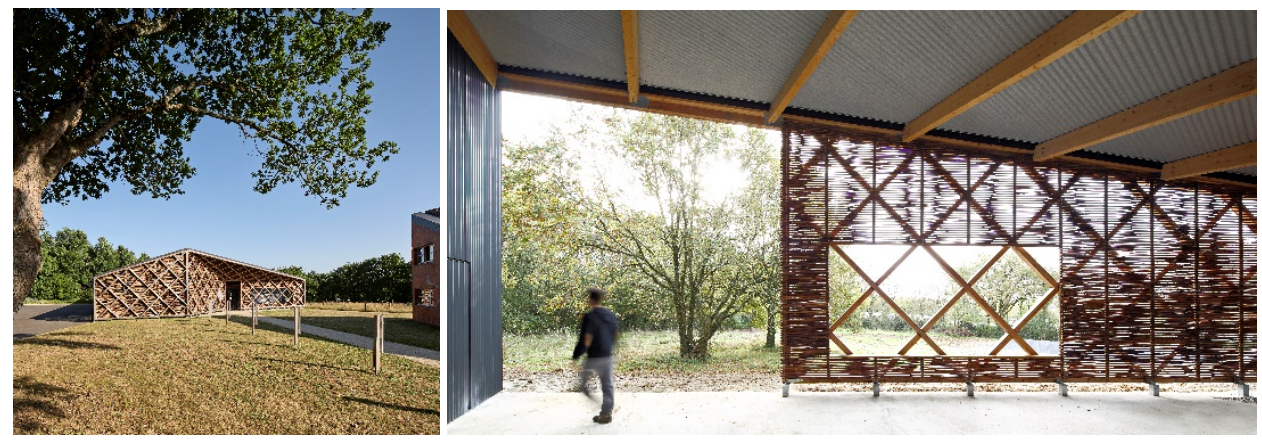

Fig. 3. Lycée Rieffel, Mabire\&Reich Agency, Saint Herblain, France.

\footnotetext{
* Antoine Mabire, architect, interview conducted on 20 December 2018.
} 

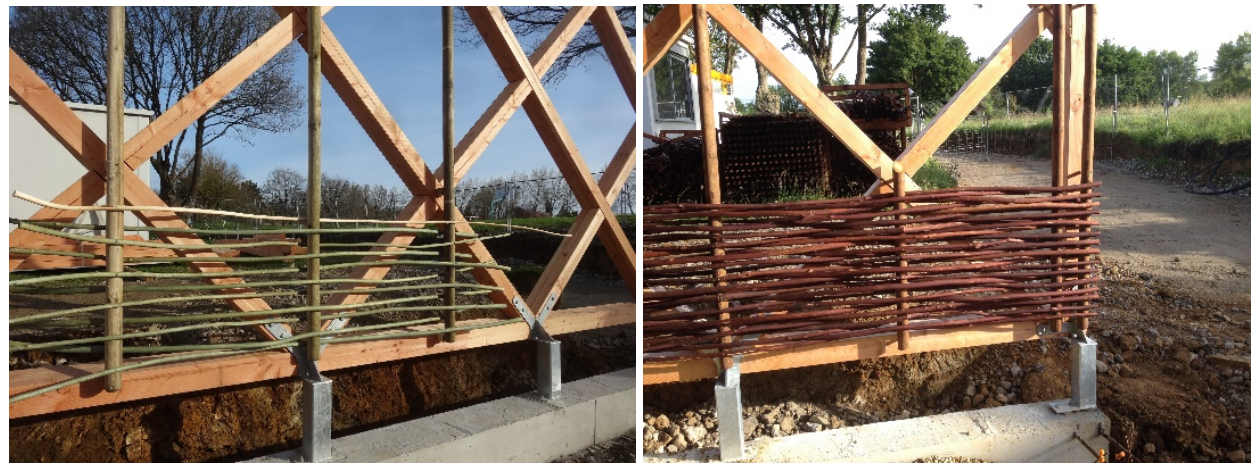

Fig. 4. Tests for weaved wicker, Lycée Rieffel, Mabire\&Reich Agency, Saint Herblain, France.

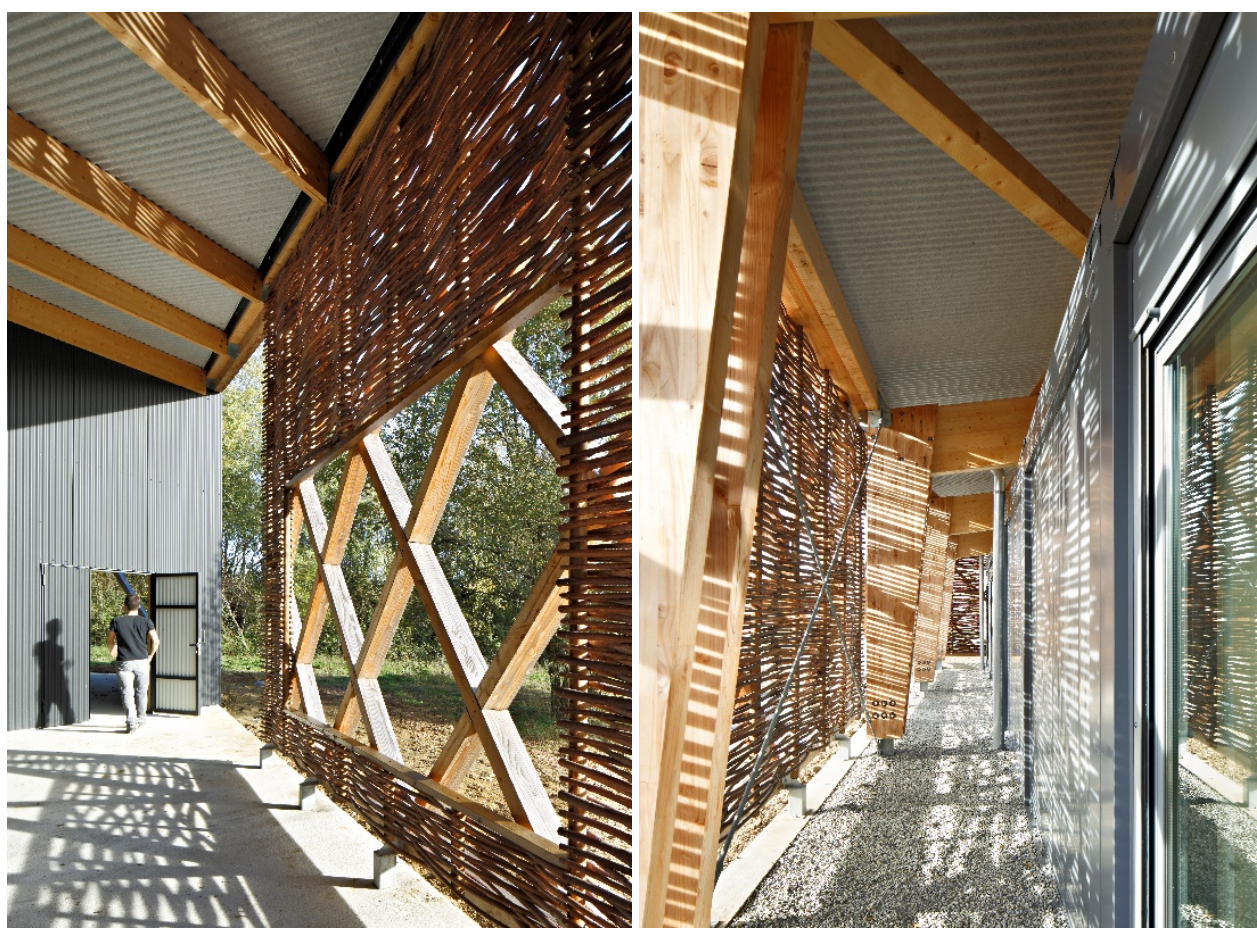

Fig. 5. Ambiances in the building Lycée Rieffel, Mabire\&Reich Agency, Saint Herblain, France.

However, as architecture is defined as the passage from a conceptual idea to its materialisation, working via the material seems to ensure a deeper reflection on the sensory qualities of space, to reach "a harmony between the project and the materiality, until we find a perfect agreement between the programme, the form and the material." [11] (p.85), which goes through "creativity, which invites the comparison of materials, to take them out of their context or to think them under new forms and structures" [11] (p.85).

The other essential dimension in such an approach is the consideration of the lived dimension in the design process. It is the reason why, throughout the different workshop sessions, we emphasised the sensory feedback surrounding the built device. This addition in the pedagogical development aims to help the students understand more easily their experience in the process of architectural design. Indeed, it appears to us necessary to give the students the dimension of the body experience of space to "humanise architecture" [14] (p.104). This concern is connected to different fields of activity around architectural design, 
whether via materials, as it is presented here, or via the physical reading of a place, like for example at ENSA Strasbourg. The professors explain: "Training in sensory experiences of space could without a doubt fill the gap created by the abandonment of this physical dimension from the project. It should raise awareness of the magic about reality, and enable practices of project that integrate the imagined experience of architecture in a better way." [15] (p.306).

The workshop sessions presented here have been taking place at the Graduate School of Architecture of Nantes since 2014. However, as an optional course, it is catered for a limited number of students. For this reason, given the interest it has for all the students of the school and the professors, we decided to implement built devices in a location of the school that is frequently visited, as an exhibition over a few days, to give time to discover the visible material in a more dynamic way than in a material library, but also to test the built devices and experience the proposed ambiances to uncover the invisible material. This workshop has led to fruitful collaborations between professor-architects and manufacturers, between manufacturers and students, and even collaborations between designers, manufacturers and students that went beyond the frame of the course, to become a professional setting of architectural production. This allowed to start an evolution of the design process around the involvement of stakeholders during different stages of the project. The multiplicity of experiences represents a wealth of knowledge about visible materials, and in terms of corpus constitution about sensory experiences, which will support architectural design in its sensory, aesthetic and poetic dimension.

\section{References}

1. V. Lebois, D. Laburte, Ambiances, 4 (2018)

2. S. Malfroy, Faces, 67, 4 (2010)

3. J.C. Prinz, O. Gerval, Matières et matériaux : architecture, design et mode (Eyrolles, Paris, 2012)

4. G. Chelkoff, Faces, 67, 18 (2010)

5. L. I. Kahn, Silence et lumière (Editions du linteau, Paris, 1996)

6. G. Chelkoff, Ambiances, 4 (2018)

7. T. Ando, Du béton et d'autres secrets de l'architecture (L'Arche, Paris, 2007)

8. P. Zumthor, Atmospheres: architectural environments - surrounding objects (Birkhäuser, Bâle, 2006)

9. X. Bonnaud, L'expérience architecturale : réflexion sur une notion, points de vue sur une discipline (Université Paris 8 Vincennes - Saint Denis, 2013)

10. N. Tornay, Vers des outils d'aide à la conception pour intégrer les dimensions techniques, écologiques et sensibles des matériaux de construction (LRA, Toulouse, 2011)

11. H. Manfred, D. Hans, Z. Martin, Matérialité (Birkhäuser, Bâle, 2007)

12. P. Von Meiss, De la forme au lieu + de la tectonique, Une introduction à l'étude de l'architecture (PPUR, Paris, 2012)

13. A. Picon, La matérialité de l'architecture (Parenthèses, Marseille, 2018)

14. A. Aalto, La table blanche et autres textes (Parenthèses, Marseille, 2012)

15. V. Lebois, D. Laburte, Ambiances, tomorrow, 301 (2016) 